Journal of Research in Interprofessional

Practice and

Education

Vol. 5.1

March 2015
Journal of Research in Interprofessional Practice and Education (JRIPE)

Vol. 5.1

(C) 2015

Corresponding author: Yvonne Marie Colgrove. Email: ycolgrove @kumc.edu

\section{The Effects of Intraprofessional Collaborative Case-Based Learning: A Cohort Study of Student Physical Therapist and Physical Therapist Assistant Perceptions of the Physical Therapist Assistant's Role}

\author{
Yvonne Marie Colgrove, PhD; Lori Maria Walton, $\mathrm{PhD}$; \\ \& Lisa Delores VanHoose, PhD
}

\begin{abstract}
Background: The changing nature and complex regulation of healthcare require the efficient use of resources, including the appropriate delegation and supervision of the physical therapist assistant (PTA). Knowledge of the scope of PTA practice introduced in the academic curriculum is mandated for entry-level practice. This study assessed the effect of a collaborative case-based educational intervention within the didactic curriculums of a physical therapy (PT) and PTA program on student knowledge of PTA scope of practice.

Methods and Findings: A pre- and post-test research design was used. Students completed a validated survey exploring their perceptions of the PTA role before beginning the case study. The case study was a classroom assignment followed by instructional prompts requiring interactions between student cohorts three times over four weeks. Following case study completion, students completed the same survey. Independent and paired samples $t$-tests detected significant differences between and within groups $(p \leq .05)$.

Conclusions: Based on the results, the case-based instructional model was efficacious in teaching both student cohorts about the role of the PTA. The impact was greater on the accuracy of the PT students, but PTA students became less uncertain in their perceptions. The effect of the clinical learning environment should be investigated to determine the impact on student perception of PTA role delineation following didactic instruction.

Keywords: Role delineation; Case-based collaboration; Student perception;

Physical therapy
\end{abstract}

\section{Introduction}

The delivery of physical therapy services has relied on support from physical therapist assistants (PTAs). In 1967, the American Physical Therapy Association (APTA) House of Delegates established guidelines for the utilization of the PTA, but the evolution of the physical therapist's practice has produced a continual expansion of the PTA's role. Guidelines for PTA utilization are located in several APTA documents that state physical therapy interventions must be provided under a physical therapist's (PT's) supervision [1,2] and exclude evaluation skills [1]. The Evaluative 
2

Student Perceptions of the PTA's Role

Colgrove, Walton, \& VanHoose

Journal of Research in Interprofessional Practice and Education

Vol. 5.1

March 2015
Criteria for Accreditation of Education Programs for the Preparation of PTAs augments the PTA role to perform components of data collection in 14 areas of physical therapy practice essential for competently implementing a plan of care [3]. The PTA role delineation in data collection included recognizing and recording but not assessing changes within areas as outlined in previous documents [1,2]. Exclusionary guidelines for PTA practice emphasize that assessment skills [4] and certain intervention skills [5] are beyond the scope of practice. The Normative Model of PTA Education Version 2007 [6] and the Minimum Required Skills of PTA Graduates at Entry-Level [7] provide the current level of specific skills and competence expected of contemporary PTA graduates. The PTA Exam Blueprint [8] provides further clarification regarding practice patterns. The guidelines contained in the aforementioned documents primarily address patient care activities and are largely silent about administrative activities. However, the PTA Exam Blueprint encourages conversation about the PTA's role outside direct patient care activities by acknowledging possible roles in management and research positions.

Few studies address the efficacy of instructional methods focused on PTA utilization. Most learning occurs with lectures and clinical internships, but didactic instruction on the role of the PTA occurs independently due to the differences between professional and technical skills based on academic degrees. Therefore, didactic instruction occurs without interactions between PT and PTA students. Educators in physical therapy expect isolated didactic instruction in the appropriate use of the PTA to serve as the cornerstone for clinical internships and future practice. Although content about PTA roles may be delivered in the classroom, the initial contact between the PT and PTA students and therapists traditionally transpires during clinical internships. PTs must continually interpret multiple documents and evaluate the competency of the PTA(s) under their direction. The subjectivity of "competency" can result in confusion about PTA practice patterns, although state practice acts provide a rudimentary definition of "appropriate utilization." Utilization guidelines are available, but practice patterns vary significantly among facilities. The expansion of the PTA role and multiple practice descriptions serve as possible factors in the improper utilization of the PTA in various clinical settings. Variations in clinical practices and perceptions of roles can affect intraprofessional and interprofessional relationships, and subsequently public healthcare outcomes [9].

Researchers have documented inappropriate practice modelling within clinical internships and the first year of employment by PT students [10,11], along with inconsistencies in the perception of the PTA's scope of practice [12]. Since confusion about physical therapy delivery exists within and outside the profession [13-16], educators should provide strategies for training PTA and doctorate of physical therapy (DPT) students on the proper role of the PTA outside of clinical experiences. Collaborative learning enables educators to mold professional interactions between PTA and PT students prior to clinical internships and decrease the likelihood of erroneous PTA utilization. Correct utilization of the PTA promotes quality services, efficient outcomes, adherence of practice guidelines, and most importantly, positive healthcare outcomes. Collaborative cased-based learning may provide a greater understanding 
Student Perceptions of the PTA's Role

Colgrove, Walton, \& VanHoose

Journal of Research in Interprofessional Practice and Education

Vol. 5.1

March 2015

\section{Journal of Research in Interprofessional Practice and Education}

of the PTA role. The aim of this study is to determine the efficacy of collaborative casebased learning on improving the understanding of the PTA's role between DPT and PTA curriculums. We hypothesize that collaborative case-based learning increases appropriate perceptions of the role of the PTA for both PTA and DPT students.

\section{Methods}

The study was approved by the Institutional Review Board (11739) at the PT academic institution.

\section{Participant characteristics}

The study was integrated into a spring semester course of two academic programs. Participants were PT students in the first year of doctoral studies at University of Kansas Medical Center (Kansas City, KS) or PTA students in the second year of instruction at Washburn University (Topeka, KS). Students were excluded if they were not enrolled in the courses.

\section{Questionnaire}

Robinson et al. [12] created a questionnaire to assess perceptions of the PTA's scope of practice. The validated questionnaire focused on four practice areas: patient evaluation, treatment planning, administrative activity, and treatment implementation $[12,16]$. The answers were updated by three independent experts using current reference documents [1-8] to reflect contemporary practice. The pre-test questionnaire was distributed to all students one week before the case-based project, and an identical post-test questionnaire was issued to the students one week after the completion of the case-based assignment. Consent to participate was implied through submission of the de-identified questionnaire. Respondents identified perceptions of practice by answering “yes," "no," or "do not know."

\section{Collaborative case-based educational intervention}

Students were randomly divided (ANGEL version 7.4, ANGEL Learning Management Suite, Indianapolis, IN) into groups based on a 1:2 PTA to DPT student ratio. Students completed the case-based course assignment designed to promote PTA and DPT student communication for patient care delivery. The case study was a patient with musculoskeletal lower extremity pain requiring modalities and therapeutic exercise interventions. The patient would later have a fall adding more trauma. The case study addressed questionnaire patient evaluation items 1-6, 9, 13, 16, 20, and 23-24; treatment planning items 1-6, 8-14; and treatment implementation items $1-6,8,10,12,16$, and 19 . The first week of the intervention, DPT students completed case-study evaluations and communicated the plan of care (POC) to the PTA students. PTA students clarified the POC and communicated with the DPT students using the APTA problem-solving algorithm [17]. Instructors provided periodical information containing triggers about the patient's status that prompted communication between the DPT and PTA students. PTA students completed weekly patient progress notes. DPT students completed a reassessment of the patient during weeks 
Student Perceptions of the PTA's Role

Colgrove, Walton, \& VanHoose
Journal of Research in Interprofessional

Practice and Education

Vol. 5.1

March 2015
Journal of Research in Interprofessional Practice and Education

2 and 4, and communicated appropriately with the PTA students. After the fourth week, a discharge note was completed after discussion between the PTA and DPT students. The weekly progress note, reassessment, and discharge note were mandatory course assignments that were independently and blindly graded. Assignments were not collected for use in this study.

\section{Statistical analysis}

Data analysis was performed using SPSS 17 (SPSS for Windows, Chicago, IL) by a blinded researcher not involved with the intervention. Data were described using percentages, means, standard deviations, and frequency distributions. Changes were noted above three percentage points. Answers that were left blank or had two answers given were not included in the analysis (* indicates a missing single answer in Tables $2-5)$. Independent and paired samples $t$-tests were used to reveal differences between and within groups. Statistical significance was determined by a $p$-value $<.05$. Levine's test for equality of variances was used to determine $p$-value based on valid equal variances assumptions.

\section{Results}

\section{Response Rate}

The pre-test questionnaires were returned by $100 \%$ of the DPT $(N=37)$ and PTA $(N=19)$ students. Post-test questionnaire response rates were $100 \%$ of PTA students $(N=19)$ and $97.3 \%$ of DPT students $(N=36)$.

\section{Participant characteristics}

Participant characteristics are summarized in Table $1 .^{1}$ The gender distribution was relatively even between the two student groups, with $13-16 \%$ being male and $84-89 \%$ being female. No DPT students had practiced as a PTA. On average, $48 \%$ of DPT students had PT technician experience, whereas 35\% of PTA students had PT technician experience. Since both DPT and PTA students had clinical experiences prior to the collaborative case study, reports of prior PT/PTA clinical interactions were fairly high. At the initiation of the project, $86 \%$ of DPT students had reported clinical interactions with PTAs, whereas $79 \%$ of PTAs had clinical interactions with PTs. There were no significant differences between the groups' gender and clinical experience characteristics. In the first year of DPT curriculum, $92 \%$ of DPT students stated that PTA scope of practice instruction was not included in curriculum, and $6 \%$ were uncertain. This was not unexpected, as students had not yet had the content at that point in the curriculum. Post-test results indicated that $28 \%$ of DPT students thought PTA scope of practice was contained in the curriculum. Before the project, $84 \%$ of PTA students reported having PTA scope of practice in their curriculum pretest, and after the project $100 \%$ perceived it was in the curriculum.

\section{Questionnaire results}

\section{Patient evaluation (PE)}

At baseline, the PTA cohort correct responses (accuracy) were below 75\% on 17 of the 
5

Student Perceptions of the PTA's Role

Colgrove, Walton, \& VanHoose

Journal of Research in Interprofessional Practice and Education

Vol. 5.1

March 2015 items and were $75 \%$ or above on 7 of the items (Table 2). At post-test, 11 items were $75 \%$ or above, with a reduction to 13 items below $75 \%$. The PTA cohort improved on 12 of 24 items (Figure 1A), although the difference did not achieve statistical significance. PE item 3 had the largest change in accuracy, from $63.2 \%$ to $94.7 \%$. The overall average improvement was $14.5 \%$. Eight of the items declined in accuracy an average of $-10.8 \%$, with the highest decline on PE15 of $-32.7 \%$ (Figure 1B). Subdividing items into those within or outside the PTA role reveals the PTA students improved in 9 of the 12 items that are encompassed in the PTA role, while improvement was noted in two of the areas that are not in the PTA role. In the items not correctly marked, two were within the PTA role, while six were not within the classified PTA scope.

At baseline, the DPT cohort scored below $75 \%$ on 22 of the items and above $75 \%$ on two items. At post-test, the DPT students displayed above $75 \%$ on seven items. The DPT students improved in the amount of correct responses in 14 of 24 items, with three items considered significant (Figure 1D). Three items remained the same and seven items declined (Figure 1E). The most improvement was on PE3, PE14, and PE12, with increases of $42.9 \%, 38.9 \%$, and $36.6 \%$, respectively. The average improvement was $24.8 \%$, while the average decline was $-7.1 \%$. For items that are within the PTA role, DPT students improved on 11 of 12 items. Outside the PTA role, the DPT students improved on three items, while declining on 7 of the 12 items.

Comparing cohorts at baseline, PTA students scored higher on 12 items than DPT students, mostly within the PTA scope, with PE4 $(p=.021)$ and PE20 $(p=.050)$ being significantly higher. DPT students scored higher on eight items that were outside the PTA scope. Following intervention, both groups improved on nine items that were all within the PTA role and declined on three items that were outside the role of the PTA. All other items showed different trends between groups. More items improved and showed a larger margin of improvement than declination in both groups. For the 12 items that were directly addressed by the case study, PTA students improved an average of $13.7 \%$ on seven items and declined on four items an average of $-6.6 \%$. DPT students improved an average of $24.9 \%$ on nine items and declined an average of $-1.4 \%$ on three items. The DPT students made more gains than the PTA students in this section.

The uncertainty displayed by answering "do not know" was much reduced in both PTA and DPT groups following intervention (Figure 1C and 1F). The PTA group improved on 16 items, and had more uncertainty in two items. The DPT group improved in the level of uncertainty on all items, except one that had no uncertainty to begin with.

\section{Treatment planning (TP)}

PTA cohort accuracy was above $75 \%$ in six of the items and below in the remaining eight items initially. The PTA cohort improved on of 6 of the 14 items for an average of $11.5 \%$ and decreased correctness on 7 items for an average of $-15.2 \%$ (Figure 2AB, Table 3). Two items within the PTA scope of practice improved, while one decreased. Items outside the PTA scope improved on 3 of the 12 items while decreasing on six items. 
Student Perceptions of the PTA's Role

Colgrove, Walton, \& VanHoose

Journal of Research in Interprofessional Practice and Education

Vol. 5.1

March 2015
Journal of Research in Interprofessional Practice and Education

The DPT cohort was initially above $75 \%$ on four items and improved an average of $12.6 \%$ on five items, and decreased an average of $-8.2 \%$ on six items (Figure 2DE) following the intervention. Within the PTA scope, one item improved and one decreased. Outside the scope of practice, four items improved and five declined.

At baseline, PTA students scored higher on six items while DPT students scored higher on eight items, with TP7 being significantly higher $(p=.04)$. Both groups saw increases in three items following intervention. Item 12 was significantly higher $(p=.048)$ in the PTA group, and TP2 and TP5 were significantly higher in the DPT group. Three items decreased in both groups, with item three being significantly lower in the PTA group $(p=.009)$. The only item (TP7) not included in the case study saw an improvement of $12.8 \%$ in the PTA student group and a small decline of $-4.2 \%$ in the DPT student group. Uncertainty was improved in nine of the items in the PTA group and ten of the items in the DPT group, with the remaining items showing no relative change (Figure $2 \mathrm{C}$ and $2 \mathrm{~F}$ ). Both groups of students made similar gains in this section.

\section{Treatment implementation (TI)}

The PTA cohort improved on 10 of the 25 items and declined on five for an average of $-10.5 \%$ (Figure $3 \mathrm{~A}-\mathrm{B}$, Table 4 ). The PTA group scored above $75 \%$ on 18 items both pre- and post-test. Changes in accuracy averaged $15.8 \%$ and was notably improved in TI23 at $41.2 \%(p=.007)$. Of the items within the PTA scope of practice, nine were improved, and four decreased.

The DPT students scored above $75 \%$ on 12 of the items at baseline. The DPT cohort improved on 19 items, with 18 of them being within the scope of PTA practice for an average improvement of $12.6 \%$. Eight of the items were significantly improved (Figure 3D). TI21 showed highest percentage improvements of $28.8 \%$. This group declined on three items an average of $-6.9 \%$ (Figure $3 \mathrm{E}$ ). Of the items outside the PTA scope, two decreased and one increased.

At baseline, PTA students scored higher on 15 items and DPT students scored higher on six items, with TI3 being significantly higher $(p=.012)$. The remaining four items were the same. With the intervention, both groups increased on seven items within the scope of PTA practice and one item outside the PTA scope. Fabrication of adaptive equipment was decreased in both groups. With items directly addressed by the case study, PTA students rated $100 \%$ on seven items pre- and posttest, so improvements were only noted in the remaining four items, with an average improvement of $11.9 \%$. They did not decline in any of the items addressed by the case study. The DPT students rated $100 \%$ on three of the items pre- and post-test. The item on executing therapeutic exercise declined $-5.6 \%$, while all the other eight remaining items improved on average $8.1 \%$. The PTA students made slightly more gains than the DPT students in this section.

The DPT cohort decreased the level of uncertainty on all the items that were not at $100 \%$, while the PTA cohort decreased the level of uncertainty on 12 items as three items increased the level of uncertainty, none which were included in the case study baseline (Figure 6C and 6F). 
7

Student Perceptions of the PTA's Role

Colgrove, Walton, \& VanHoose

Journal of Research in Interprofessional Practice and Education

Vol. 5.1

March 2015

\section{Administrative activity (AA)}

In the area of administrative activity, five items are clearly addressed within the documents. Of these five items, the PTAs improved on two an average of $12.4 \%$ and decreased on three an average of $-11.4 \%$. The DPT students improved on one item $3.2 \%$ and decreased on three items an average of $-4.6 \%$. None of the administrative activity items were addressed by the case study, and none changed significantly in either group. The PTA students made more gains than DPT students in this section.

We report the trends of student perceptions on the remaining items because they are not addressed in reference documents, and clinical practice, particularly in skilled nursing settings, suggest that PTAs serve in management positions and are thus able to perform many of the tasks listed. The majority of both groups felt it was outside the scope of PTA practice to perform human resource (HR) management of the PT or develop physical therapy policies and procedures, although they became a little less certain after the intervention (Figure 4A, Table 5). Most students felt it was acceptable for PTAs to perform departmental program development and research tasks. Uncertainty declined and the perception of acceptability was increased after the intervention (Figure 4B). PTA students initially felt stronger that fiscal management and HR management of the PTA was outside the PTA role, but following the intervention they became less convinced or more accepting of the notion that it could be within PTA practice (Figure 4C). The DPT students were more split in their opinions than the PTA students on these items. The DPT students were more accepting of PTAs being involved in HR management of their peers initially, but became less convinced after the intervention. The DPT students initially were less accepting of the PTA role in fiscal management, but became less certain and more accepting following the intervention. Interestingly, PTA students had higher levels of initial acceptance and less uncertainty in the HR functions associated with a PTA (AA8 in Figure 4C) than they did with a PT aide (AA11 in Figure 4D). Post intervention, the PTA students became less accepting of the PTA role in managing the PT aide. DPT students were split fairly evenly in yes, no, and I don't know answers that were outside the scope of practice initially, and at post-test they became slightly more accepting and uncertain of the PTA role in PT aide management. For development of quality assurance program (AA12), both groups became more accepting and less uncertain of the PTA's role in this activity following intervention. However, the PTA students overall had levels of less acceptance overall than DPT students.

\section{Discussion}

\section{Survey revision and comparison}

Revision to the original survey [12] was done in the patient evaluation and treatment implementation sections. In the revised questionnaire treatment implementation section (Appendix A), fabricate adaptive equipment is no longer found in the current documents, which now clearly define apply, adjust, instruct, and check effectiveness of adaptive equipment/device, so this answer was changed to "no." The remaining "yes" answers remained the same. Of the original "no" items, six items were changed to yes based on current references (Appendix 1). Neurodevelopmental treatment sessions 
8

Student Perceptions of the PTA's Role

Colgrove, Walton, \& VanHoose

Journal of Research in Interprofessional Practice and Education

Vol. 5.1

March 2015 are perhaps dated to the use of Neuro-Development Treatment (NDT), which is regulated by a private organization. Certification by this organization is allowed by PTs but not PTAs; however, the organization allows training of PTAs and provides a public list of PTAs using the technique. The current approach to neurological disorders includes motor control and motor learning training, which is clearly indicated both as neuromotor development training and motor function training as being within the PTA role, so this answer was changed to yes. Sensory re-education stimulation is also referred to as sensory re-training [18] and is also clearly indicated now as a PTA skill in documents, so it was also changed to yes. It should also be recognized that wound debridement could be either yes or no since certain components of wound debridement are allowed while others are prohibited by the APTA and state practice acts.

Patient evaluation section items with the terms evaluation and interpret are outside the realm of PTA activities so these remain no. PTAs are able to assist with data collection by performing tests and measures, which is a part of "assessment." However, evaluation is done at the end of inquiry to see if there has been a change in data, to determine a diagnosis and/or course of action. It is the process of making judgments, which is considered strictly in the role of the PT. The treatment planning section remained the same, but there is debate around the terms selection or modification of methods, settings, or techniques.

It is in the PT's scope to determine what the PTA can do in making selections or modification by how they write the patient plan of care. If the plan of care contains specific information pertaining to methods, settings, or techniques, then the answer would be no. If the POC is written broadly, then given the contextual factors, like PTA experience, that guide the PT's decision to direct patient care to the PTA, the answer could be yes [4,17]. The administrative activity section only contains four definitive yes answers, but two of these could arguably be the function or role of a PT aide. One item is a definitive no answer, where the PTA may not delegate treatment tasks to an aide but rather only non-treatment tasks. The remaining items have no support either way, although many PTAs function in managerial roles where they may be performing some administration and management duties.

Comparing our findings with a study measuring perceptions of practicing PTs [12] in the unchanged questionnaire items, half of the items reflecting the scope of PTA practice in the patient evaluation were similar and the other half were actually higher in the DPT students. However, in the items outside the scope of PTA practice, the seasoned PTs scored higher than students. In the treatment planning section, most scores were similar on the items in the PTA scope of practice, except modify treatment techniques, which was lower in students. Since the students had just learned about specificity in writing the treatment plan, it is possible that this was a consideration, which is supported by the fact that the DPT students scored higher than practicing PTs on designing a POC and on setting and changing goals, which are outside the PTA scope of practice. The experienced PTs scored higher on the remaining items not within the PTA scope of practice in treatment planning. For unchanged treatment implementation items, experienced PTs scored higher on items that were within the PTA scope of practice. Practicing PTs felt more strongly that PTAs should not be per- 
9

Student Perceptions of the PTA's Role

Colgrove, Walton, \& VanHoose

Journal of Research in Interprofessional Practice and Education

Vol. 5.1

March 2015 forming administrative activities in the "silent" areas than did DPT students. Although students are influenced by educational level and content in the formulation of their perceptions, which influenced the accuracy of their responses, they had very limited influence of experience. However, the experienced clinicians may be influenced by organizational culture or maintaining outdated practice patterns that have not kept up with the progression of the profession. Consideration should be made for investigating perceptions of current clinicians with a modified survey reflective of contemporary practice, as the physical profession, and thus practice patterns, have evolved over the past 15 years. It would allow for assessment of needed educational efforts for both current and future clinicians in the PT profession, as proper delegation has significant ethical and compliance implications.

Comparing our findings with the previous survey that measured the perceptions of practicing PTAs [16], the PTA students scored better on three unchanged items in the patient evaluation section than practicing PTAs. In the items outside the scope of PTA practice, the practicing PTAs scored higher or similarly in most items. In the treatment planning section, PTA students scored lower on most items outside the PTA scope of practice, although the PTA students scored higher in the goals and plan of care items. As with the DPT students, the PTA students scored lower on the treatment technique modification item than the practicing clinicians. In the treatment implementation section, the scores were similar on 8 items, with the PTA students scoring higher on six items and lower on four items in the PTA scope of practice. In the administrative activity section, the PTA students appeared more conservative than practicing PTAs in providing yes answers to most of the items analyzed, with the exception of participation in research. As with any cohort study, selection and recall biases may influence results and interpretation of the impact of interventions, which is a limitation of this study. A multisite study is warranted to minimize those influences. A national study of new graduates would capture the understanding of PTA scope of practice.

\section{Collaborative case study as an educational intervention}

DPT students were generally less informed about the PTA role than the PTA students. Overall results from intervention show a greater amount of items that showed improvement than declined in all of the sections except treatment planning for both groups. There was a greater overall percentage of improvement versus declination in all sections for both student groups. Most notably, uncertainty improved in all sections, which seemed more prominent in DPT students, with very few items becoming more uncertain. The DPT students had more improvement in the area of patient evaluation than PTA students. Given the DPT students had no curricular content and minimal clinical exposure, the DPT students' perception may have revolved around the idea that PTAs are not to be involved in any of the process leading up to evaluation. Since PTA students have an overall better understanding of the breadth and depth of their role than the DPT students, it is not surprising that they did not see as much change in this area. It should be noted that PTAs had more clinical education experience than the DPT students, which may also have played a role. The 
Student Perceptions of the PTA's Role

Colgrove, Walton, \& VanHoose

Journal of Research in Interprofessional Practice and Education

Vol. 5.1

March 2015

\section{Journal of Research in Interprofessional Practice and Education}

PTA students had slightly more improvement than DPT students in treatment implementation. The case study provided ample opportunity to address a significant portion of the items listed in this section, which could have provided clarification for specific items for the PTA students. The PTA students had more improvement in the administrative activity section, although the case study did not address any of these items. Exposure to particular clinical settings, especially in skilled nursing facilities, may have influenced the student perceptions of the PTA role in management, which was not tracked in this study. PTA students were less accepting of the PTA in administrative roles than the DPT students overall.

\section{Limitations}

We acknowledge the limitations of our study design. The pre- and post-assessments occurred within one month. It is likely that recall bias could have influenced our results due to the short time frame. Selection bias is always a concern with any sample of convenience or non-randomized study. For these reasons, we chose to investigate and report the change in scores for the readers to independently assess the impact of our intervention. Our study cohorts were from schools within the same state and only consisted of one DPT and PTA program. Although our results strongly support the use of collaborative cased-based instructions to instruct and reinforce the appropriate use of the PTA, a multisite study is needed to validate our findings and to support the use of this instructional strategy across the vast and very diverse DPT and PTA programs.

\section{Conclusions}

Our findings suggest that accuracy and confidence in roles may be positively impacted by collaborative case-based learning opportunities that could easily be applied to interprofessional teaching. Following intervention, patterns of reduced uncertainty could indicate the experience helped solidify confidence in answers. Since more answers were improved, formulating opinions in a safe context where both healthcare professionals are learning may be of benefit. In educating future professionals, intraprofessional educational opportunities appear to have benefit in promoting the understanding of role delineation. It would be worth investigating the influence of the clinical environment on learning about roles of other healthcare professionals. Collaboration during clinical experiences between intraprofessional students helps develop relationships and promote understanding of each other's roles, which can help prepare students for future collaborative practice, but learning is subject to environmental influences [19]. Collaborative case-based interprofessional experiences have been shown to positively impact healthcare students toward learning from and with practicing healthcare professionals [20] and students [21]. Other methods have been shown to improve understanding of other healthcare professionals; even those within one's own profession are case-based simulations [22-23] and faculty modeling [24]. There are nuances of clinical practice that cannot be ignored and that are difficult to address in academic preparation, which should be further investigated. Case-based studies designed to promote communication of patient care 
JRIPE

11

Student Perceptions of the PTA's Role

Colgrove, Walton, \& VanHoose
Journal of Research in Interprofessional Practice and Education

Vol. 5.1

March 2015 should be completed in the didactic curriculum between different healthcare providers to advance student knowledge and appreciation of the role of other healthcare providers. This will serve to promote interprofessional care that ultimately benefits future patients of students.

\section{Acknowledgements}

We would like to thank all the students who compled the survey. Dr. Lori Walton is currently a faculty member at Andrews University. Research reported in this publication was supported by the Eunice Kennedy Shriver National Institute of Child Health \& Development of the National Institutes of Health under Award Number K12HD052027, for which we are grateful. The content is solely the responsibility of the authors and does not necessarily represent the official views of the National Institutes of Health.

\section{Note}

1. All tables, figures, and an appendix follow the references.

\section{References}

1. American Physical Therapy Association. (2004). Guide for conduct for the physical therapy assistant. Alexandria, VA: American Physical Therapy Association.

2. American Physical Therapy Association, House of Delegates Standards, Policies, Positions, and Guidelines. (2012). Criteria for standards of practice of physical therapy BOD S03-06-16-38. Alexandria, VA: American Physical Therapy Association.

3. American Physical Therapy Association. (2007). Evaluative criteria for accreditation of education programs for the preparation of physical therapist assistants. Alexandria, VA: American Physical Therapy Association.

4. American Physical Therapy Association, House of Delegates Standards, Policies, Positions, and Guidelines. (2009). Direction and supervision of the physical therapist assistant HOD P06-05-18-26. Alexandria, VA: American Physical Therapy Association.

5. American Physical Therapy Association, House of Delegates Standards, Policies, Positions, and Guidelines. (2009). Procedural interventions exclusively performed by physical therapists HOD P06-00-30-36. Alexandria, VA: American Physical Therapy Association.

6. American Physical Therapy Association. (2007). A normative model of physical therapist assistant education, version 2007. Alexandria, VA: American Physical Therapy Association.

7. American Physical Therapy Association, House of Delegates Standards, Policies, Positions, and Guidelines. (2009). Minimum required skills of physical therapist assistant graduates at entry level BOD G11-08-09-18. Alexandria, VA: American Physical Therapy Association.

8. Federation of State Boards of Physical Therapy, Human Resources Research Organization. (2007). Entry-level practice analysis for physical therapist assistant licensure examinations. URL: www.fsbpt.org/download/pa2006_ptafinalreport20081119.pdf [March 26, 2014].

9. Zwarenstein, Merrick, Reeves, Scott, Barr, Hugh, Hammick, Marilyn, Koppel, Ivan, \& Atkins, J. (2000). Interprofessional education: Effects on professional practice and health care outcomes. Cochrane Database of Systematic Reviews, Issue 3. Art. No. CD002213.

10. Cavallo, Cheryl L., \& Richter, Randy R. (2004). Attitudes of physical therapist students toward physical therapist assistants before and after full-time clinical internships. Journal of Allied Health, $33(1), 10-17$.

11. Sabus, Carla. (2008). The effects of modeling evidence-based practice during the clinical internship. Journal of Physical Therapy Education, 22, 74-84.

12. Robinson, Andrew J., McCall, Michael, DePalma, Mary T., Clayton-Krasinski, Debra, Tlngley, Shannon, Simoncelli, Suzann, \& Harnish, Lisa. (1994). Physical therapists' perceptions of the roles of the physical therapist assistant. Physical Therapy, 74, 571-582. URL: http://ptjournal .apta.org/content/74/6/571 [March 7, 2014]. 


\section{JRIPE}

Student Perceptions of the PTA's Role

Colgrove, Walton, \& VanHoose

\section{Journal of Research in Interprofessional Practice and Education}

13. American Physical Therapy Association. (2011). PT/PTA teamwork: Models in delivering patient care. URL: http://www.apta.org/SupervisionTeamwork/Models/ [March, 7 2013].

14. Bashi, Harriette L., \& Domholdt, Elizabeth. (1993). Use of support personnel for physical therapy treatment. Physical Therapy, 73, 421-436. URL: http://ptjournal.apta.org/content/73/7/421 [March 7, 2014].

15. Resnik, Linda, Feng, Zhanlian, \& Hart, Dennis L. (2006). State regulation and the delivery of physical therapy services. Health Services Research, 41(4 Pt 1), 1296-1314.

16. Robinson, Andrew J., DePalma, Mary T., \& McCall, Michael. (1995). Physical therapist assistants' perceptions of the documented roles of the physical therapist assistant. Physical Therapy, 75, 1054-1066. URL: http://ptjournal.apta.org/content/75/12/1054 [March 7, 2014].

17. Crosier, Janet. (2010, September). PTA direction and supervision algorithms: Step by step problem solving diagrams to guide PTs and PTAs. PT in Motion, 47-50.

18. Phillips, Ceib, Blakey, George, \& Essick, Greg K. (2011). Sensory retraining: A cognitive behavioral therapy for altered sensation. Atlas of Oral \& Maxillofacial Surgery Clinics of North America, 19(1), 109-118.

19. Jung, Bonny, Salvatori, Penny, \& Martin, Adele. (2008). Intraprofessional fieldwork education: Occupational therapy and occupational therapist assistant students learning together. Canadian Journal of Occupational Therapy, 75(1), 42-50.

20. Wellmon, Robert, Gilin, Barbara, Knauss, Linda, \& Inman Linn, Margaret. (2012). Changes in student attitudes toward interprofessional learning and collaboration arising from a case-based educational experience. Journal of Allied Health, 41(1), 26-34.

21. Cavanaugh, James T., \& Konrad, Shelley, C. (2012). Fostering the development of effective personcentered healthcare communication skills: an interprofessional shared learning model. Work, 41(3), 293-301.

22. Heuer, Albert J., Geisler, Sheryl, Kamienski, Mary, Langevin, Denise, \& Maillet, Julie O'Sullivan. (2010). Introducing medical students to the interdisciplinary health care team: Piloting a casebased approach. Journal of Allied Health, 39(2), 76-81.

23. Leonard, Brenda, Shuhaibar, Elaine L.H., \& Chen, Ruth. (2010). Nursing student perceptions of intraprofessional team education using high-fidelity simulation. Journal of Nursing Education, 49(11), 628-631.

24. Selle, Katie M., Salamon, Kathleen, Boarman, Regina, \& Sauer, Janet. (2008). Providing interprofessional learning through interdisciplinary collaboration: The role of "modelling." Journal of Interprofessional Care, 22(1), 85-92. 


\section{JRIPE}

13

Student Perceptions of the PTA's Role

Colgrove, Walton, \& VanHoose
Journal of Research in Interprofessional Practice and Education

Table 1

\section{Participant characteristics}

\begin{tabular}{|c|c|c|c|c|}
\hline Characteristic & $\begin{array}{l}\text { PT pre-test } \\
(N=37)\end{array}$ & $\begin{array}{l}\text { PT post-test } \\
(N=36)\end{array}$ & $\begin{array}{l}\text { PTA pre-test } \\
(N=19)\end{array}$ & $\begin{array}{l}\text { PTA post-test } \\
(N=19)\end{array}$ \\
\hline $\begin{array}{l}\text { Gender } \\
\text { Male } \\
\text { Female }\end{array}$ & $\begin{array}{l}13.5 \%(N=5) \\
86.5 \%(N=32)\end{array}$ & $\begin{array}{l}13.9 \%(N=5) \\
86.1 \%(N=31)\end{array}$ & $\begin{array}{l}15.8 \%(N=3) \\
84.2 \%(N=16)\end{array}$ & $\begin{array}{l}15.8 \%(N=3) \\
84.2 \%(N=16)\end{array}$ \\
\hline PT technician experience & $48.7 \%(N=18)$ & $47.2 \%(N=17)$ & $36.8 \%(N=19)$ & $33.3 \%(N=18)$ \\
\hline Practice as a PTA & $0 \%$ & $0 \%$ & & \\
\hline $\begin{array}{l}\text { Knowledge of PTA } \\
\text { scope of practice } \\
\text { No } \\
\text { Yes } \\
\text { DNK }\end{array}$ & $\begin{array}{l}91.7 \%(N=33) \\
2.8 \%(N=1) \\
5.6 \%(N=2)\end{array}$ & $\begin{array}{l}66.7 \%(N=24) \\
27.8 \%(N=10) \\
5.6 \%(N=2)\end{array}$ & $\begin{array}{l}10.5 \%(N=2) \\
84.2 \%(N=16) \\
5.3 \%(N=1)\end{array}$ & $\begin{array}{l}0 \% \\
100 \%(N=18) \\
0 \%\end{array}$ \\
\hline Prior PT/PTA clinical interactions & $86.1 \%(N=36)$ & $82.7 \%(N=35)$ & $79.0 \%(N=19)$ & $79.0 \%(N=19)$ \\
\hline
\end{tabular}

Journal of Research in Interprofessional Practice and Education

Vol. 5.1

March 2015

www.jripe.org 
14

Student Perceptions of the PTA's Role

Colgrove, Walton, $\&$ VanHoose
Journal of Research in Interprofessional Practice and Education
Table 2

\section{PTA role in patient evaluation}

\begin{tabular}{|c|c|c|c|c|c|c|c|c|}
\hline \multirow{2}{*}{$\begin{array}{l}\text { PE item } \\
\begin{array}{l}\text { 1. Detect sudden changes in } \\
\text { physiological state }\end{array}\end{array}$} & \multicolumn{2}{|c|}{$\begin{array}{c}\text { PTA pre-test } \\
\% \text { correct, \% uncertain }\end{array}$} & \multicolumn{2}{|c|}{$\begin{array}{c}\text { PTA post-test } \\
\% \text { correct, \% uncertain }\end{array}$} & \multicolumn{2}{|c|}{$\begin{array}{c}\text { DPT pre-test } \\
\% \text { correct, \% uncertain }\end{array}$} & \multicolumn{2}{|c|}{$\begin{array}{c}\text { DPT post-test } \\
\% \text { correct, \% uncertain }\end{array}$} \\
\hline & 100 & 0 & 94.7 & 0 & 97.3 & 0 & 97.2 & 0 \\
\hline 2. Monitor vital signs & 89.5 & 10.5 & 100 & 0 & 91.9 & 5.4 & 97.2 & 0 \\
\hline 3. Identify architectural barriers & 63.2 & 31.6 & 94.7 & 5.3 & 43.2 & 43.2 & 86.1 & 5.6 \\
\hline $\begin{array}{l}\text { 4. Measure length/girth of body } \\
\text { segments }\end{array}$ & 84.2 & 15.8 & 100 & 0 & $69.4^{*}$ & 8.3 & 94.4 & 0 \\
\hline 5. Test gross muscle group strength & 89.5 & 5.3 & 100 & 0 & $58.3^{*}$ & 11.1 & 91.7 & 0 \\
\hline 6. Perform joint ROM tests & 94.7 & 5.3 & 100 & 0 & $63.9^{*}$ & 11.1 & 92.7 & 0 \\
\hline 7. Perform electromyography & 21.1 & 36.8 & 10.5 & 57.9 & 27.0 & 43.2 & $17.1^{*}$ & 20.0 \\
\hline $\begin{array}{l}\text { 8. Administer nerve conduction } \\
\text { velocity tests }\end{array}$ & 15.8 & 42.1 & 15.8 & 42.1 & 48.6 & 45.9 & 36.1 & 25.0 \\
\hline 9. Perform perceptual tests & $61.1^{*}$ & 27.8 & $77.8^{*}$ & 22.2 & 29.7 & 35.1 & 61.1 & 16.7 \\
\hline 10. Interpret electrodiagnostic tests & 63.2 & 31.6 & 78.9 & 10.5 & 62.2 & 29.7 & 58.3 & 22.2 \\
\hline 11. Perform sensory evaluations & $16.7^{*}$ & 5.6 & 10.5 & 10.5 & $47.2^{*}$ & 25.0 & 22.0 & 8.3 \\
\hline $\begin{array}{l}\text { 12. Perform developmental level } \\
\text { Tests }\end{array}$ & 47.4 & 36.8 & 52.6 & 36.8 & 16.2 & 43.2 & 52.8 & 11.1 \\
\hline $\begin{array}{l}\text { 13. Determine prosthetic, } \\
\text { orthotic/assistive device }\end{array}$ & $38.9^{*}$ & 27.8 & $44.4^{*}$ & 11.1 & $72.2^{*}$ & 19.4 & 69.4 & 13.9 \\
\hline 14. Test sensorimotor function & $58.8^{*}$ & 35.3 & 84.2 & 15.8 & $27.8^{*}$ & 33.3 & 66.7 & 11.1 \\
\hline 15. Perform postural evaluations & 64.3 & 15.8 & 31.6 & 0 & $41.7^{*}$ & 22.2 & $37.1^{*}$ & 8.6 \\
\hline 16. Interpret joint integrity tests & 52.6 & 15.8 & 42.1 & 5.3 & 59.5 & 32.4 & 58.3 & 19.4 \\
\hline 17. Perform cardiac stress tests & 42.1 & 36.8 & 52.6 & 36.8 & 48.6 & 29.7 & 41.7 & 16.7 \\
\hline 18. Interpret developmental tests & 57.9 & 26.3 & 57.9 & 26.3 & 62.2 & 29.7 & 66.7 & 16.7 \\
\hline 19. Test accessory joint motions & 78.9 & 21.1 & 68.4 & 15.8 & 45.9 & 24.3 & $68.6^{*}$ & 5.7 \\
\hline 20. Interpret joint ROM tests & 68.4 & 10.5 & 63.2 & 0 & 40.5 & 24.3 & 47.2 & 8.3 \\
\hline $\begin{array}{l}\text { 21. Perform specific manual muscle } \\
\text { testing }\end{array}$ & 89.5 & 0 & 89.5 & 0 & 43.2 & 27.0 & 77.8 & 8.3 \\
\hline 22. Assess muscle tone & 68.4 & 21.1 & 89.5 & 0 & 45.9 & 35.1 & 66.7 & 8.3 \\
\hline 23. Evaluate ADL ability & 26.3 & 21.1 & 21.1 & 0 & 24.3 & 29.7 & $40.0^{*}$ & 8.6 \\
\hline $\begin{array}{l}\text { 24. Determine wheelchair } \\
\text { type/features }\end{array}$ & 5.3 & 5.3 & 5.3 & 0 & 62.2 & 27.0 & 58.3 & 19.4 \\
\hline
\end{tabular}

In Tables 2-5, shaded rows indicate the items that are within the PTA scope of practice according to reference documents. Non-shaded items are considered to be outside the PTA role. ${ }^{\star}$ indicates one missing answer and ${ }^{\star *}$ two missing answers. Bold indicates statistically significant difference between pre- and post-test scores. 


\section{JRIPE}

15

Student Perceptions of the PTA's Role

Colgrove, Walton, \& VanHoose
Table 3

\section{PTA role in treatment planning}

\begin{tabular}{|c|c|c|c|c|c|c|c|c|}
\hline \multirow{2}{*}{$\begin{array}{l}\text { TP item } \\
\text { 1. Design patient plan of care }\end{array}$} & \multicolumn{2}{|c|}{$\begin{array}{c}\text { PTA pre-test } \\
\% \text { correct, } \% \text { uncertain }\end{array}$} & \multicolumn{2}{|c|}{$\begin{array}{c}\text { PTA post-test } \\
\% \text { correct, \% uncertain }\end{array}$} & \multicolumn{2}{|c|}{$\begin{array}{c}\text { DPT pre-test } \\
\% \text { correct, } \% \text { uncertain }\end{array}$} & \multicolumn{2}{|c|}{$\begin{array}{c}\text { DPT post-test } \\
\% \text { correct, \% uncertain }\end{array}$} \\
\hline & 94.7 & 5.3 & $88.9^{*}$ & 0 & 81.1 & 8.1 & 94.4 & 2.8 \\
\hline $\begin{array}{l}\text { 2. Change physical therapy goals, } \\
\text { treatment techniques }\end{array}$ & 100 & 0 & $100^{*}$ & 0 & 86.5 & 5.4 & 100 & 0 \\
\hline 3. Select traction methods/settings & 57.9 & 0 & $16.7^{*}$ & 0 & 70.3 & 13.5 & 63.9 & 11.1 \\
\hline $\begin{array}{l}\text { 4. Select electrotherapy } \\
\text { method/settings }\end{array}$ & 47.4 & 26.3 & $22.2^{*}$ & 0 & 67.6 & 10.8 & 58.3 & 11.1 \\
\hline 5. Set short-/long-term goals & 84.2 & 5.3 & $100^{*}$ & 0 & 67.6 & 16.2 & 100 & 0 \\
\hline $\begin{array}{l}\text { 6. Develop therapeutic exercise } \\
\text { program }\end{array}$ & 42.1 & 10.5 & $38.9^{*}$ & 5.6 & 54.1 & 5.4 & 30.6 & 2.8 \\
\hline 7. Plan postural drainage positions & 31.6 & 57.9 & $44.4^{*}$ & 22.2 & 45.9 & 18.9 & 41.7 & 13.9 \\
\hline $\begin{array}{l}\text { 8. Select ultrasound } \\
\text { method/settings }\end{array}$ & 26.3 & 21.1 & $11.1^{*}$ & 0 & $52.8^{*}$ & 13.9 & 44.4 & 11.1 \\
\hline 9. Design ADL plan of care & 78.9 & 15.8 & $88.9^{*}$ & 5.6 & 59.5 & 10.8 & 69.4 & 11.1 \\
\hline 10. Plan massage method/technique & 10.5 & 5.3 & $16.7^{*}$ & 5.6 & 40.5 & 29.7 & 38.9 & 13.9 \\
\hline $\begin{array}{l}\text { 11. Determine solutions to } \\
\text { architectural barriers }\end{array}$ & 15.8 & 31.6 & $11.1^{*}$ & 11.1 & 27.0 & 37.8 & 27.8 & 13.9 \\
\hline 12. Modify treatment techniques & 42.1 & 31.6 & $61.1^{*}$ & 0 & 45.9 & 13.5 & 41.7 & 11.1 \\
\hline $\begin{array}{l}\text { 13. Recommend solutions to } \\
\text { architectural barriers }\end{array}$ & 94.7 & 5.3 & $100^{*}$ & 0 & 75.7 & 16.2 & 91.7 & 5.6 \\
\hline $\begin{array}{l}\text { 14. Prepare patient, equipment, } \\
\text { treatment area }\end{array}$ & 100 & 0 & $88.9^{*}$ & 0 & 94.6 & 0 & 97.2 & 0 \\
\hline
\end{tabular}


16

Student Perceptions of the PTA's Role

Colgrove, Walton, \& VanHoose

Journal of Research in Interprofessional

Practice and

Education

Vol. 5.1

March 2015
Table 4

\section{PTA role in treatment implementation}

\begin{tabular}{|c|c|c|c|c|c|c|c|c|}
\hline Tl item & $\begin{array}{r}\mathrm{PT} \\
\% \text { corre }\end{array}$ & test & $\begin{array}{r}\text { PTA } \\
\% \text { correc }\end{array}$ & $\begin{array}{l}\text { test } \\
\text { incertain }\end{array}$ & $\begin{array}{r}\text { DP } \\
\% \text { correc }\end{array}$ & test & $\begin{array}{r}\text { DPT } \\
\% \text { correc }\end{array}$ & -test \\
\hline 1. Administer therapeutic heat/cold & 100 & 0 & 100 & 0 & $100^{*}$ & 0 & 100 & 0 \\
\hline 2. Perform therapeutic massage & 100 & 0 & 100 & 0 & 81.1 & 10.8 & 88.9 & 2.8 \\
\hline 3. Assist in ADL training & 84.2 & 15.8 & 100 & 0 & 100 & 0 & 100 & 0 \\
\hline 4. Measure/adjust canes/crutches & 100 & 0 & 100 & 0 & 83.8 & 8.1 & 97.2 & 2.8 \\
\hline 5. Execute therapeutic exercise & 94.7 & 5.3 & 94.7 & 5.3 & 81.1 & 10.8 & 88.9 & 2.8 \\
\hline 6. Administer electrotherapy & 94.7 & 0 & 100 & 0 & 100 & 0 & 94.4 & 0 \\
\hline $\begin{array}{l}\text { 7. Execute fine motor dexterity } \\
\text { exercise program }\end{array}$ & 84.2 & 10.5 & 84.2 & 15.8 & 78.4 & 21.6 & 86.1 & 8.3 \\
\hline $\begin{array}{l}\text { 8. Respond to acute changes in } \\
\text { physiological state }\end{array}$ & 89.5 & 10.5 & 100 & 0 & 91.9 & 8.1 & 97.2 & 0 \\
\hline 9. Apply dressings/supports & 100 & 0 & 94.7 & 5.3 & 73.0 & 21.6 & 94.4 & 5.6 \\
\hline 10. Administer gait training & 100 & 0 & 100 & 0 & 78.4 & 16.2 & 86.1 & 5.6 \\
\hline $\begin{array}{l}\text { 11. Perform breathing re-education } \\
\text { exercises }\end{array}$ & 84.2 & 10.5 & 78.9 & 15.8 & 81.1 & 18.9 & 86.1 & 8.3 \\
\hline 12. Administer therapeutic traction & 100 & 0 & 100 & 0 & 73.0 & 18.9 & 75.0 & 11.1 \\
\hline 13. Administer postural drainage & 63.2 & 36.8 & 73.7 & 21.1 & 56.8 & 37.8 & 77.8 & 8.3 \\
\hline $\begin{array}{l}\text { 14. Perform intermittent venous } \\
\text { compression techniques }\end{array}$ & 100 & 0 & 68.4 & 21.1 & 48.6 & 40.5 & 75.0 & 8.3 \\
\hline 15. Perform prosthetic training & 84.2 & 15.8 & 94.7 & 5.3 & 51.4 & 24.3 & 61.1 & 13.9 \\
\hline $\begin{array}{l}\text { 16. Instruct patient/family in } \\
\text { treatment-related activities }\end{array}$ & 100 & 0 & 100 & 0 & 83.8 & 10.8 & 88.9 & 5.6 \\
\hline $\begin{array}{l}\text { 17. Perform sensory re-education } \\
\text { stimulation }\end{array}$ & 84.2 & 15.8 & 89.5 & 10.5 & 51.4 & 43.2 & 77.8 & 5.6 \\
\hline $\begin{array}{l}\text { 18. Conduct prepartum/ } \\
\text { postpartum exercise program }\end{array}$ & 73.7 & 26.3 & 73.7 & 21.1 & 75.7 & 21.6 & 86.1 & 11.1 \\
\hline 19. Perform perceptual training & 78.9 & 21.1 & 94.7 & 5.3 & 62.2 & 32.4 & 77.8 & 8.3 \\
\hline 20. Perform wound debridement & 94.7 & 5.3 & 89.5 & 5.3 & 37.8 & 27.0 & 44.4 & 13.9 \\
\hline $\begin{array}{l}\text { 21. Administer } \\
\text { neurodevelopmental } \\
\text { treatment sessions }\end{array}$ & 36.8 & 57.9 & 68.4 & 31.6 & 35.1 & 43.2 & 63.9 & 13.9 \\
\hline 22. Fabricate adaptive equipment & 15.8 & 42.1 & 10.5 & 26.3 & 32.4 & 29.7 & 25.0 & 11.1 \\
\hline $\begin{array}{l}\text { 23. Administer biofeedback } \\
\text { treatments }\end{array}$ & 52.6 & 42.1 & 94.7 & 0 & 62.2 & 29.7 & 80.6 & 8.3 \\
\hline $\begin{array}{l}\text { 24. Perform oral sensorimotor } \\
\text { treatment }\end{array}$ & 5.3 & 42.1 & 5.3 & 15.8 & 8.1 & 54.1 & 13.9 & 13.9 \\
\hline $\begin{array}{l}\text { 25. Measure/fit compression } \\
\text { garments }\end{array}$ & 0 & 0 & 10.5 & 0 & 21.6 & 24.3 & 13.9 & 13.9 \\
\hline
\end{tabular}


17

Student Perceptions of the PTA's Role

Colgrove, Walton, \& VanHoose
Table 5

PTA role in administration activity

\begin{tabular}{|c|c|c|c|c|c|c|c|c|c|c|c|c|}
\hline \multirow{2}{*}{\begin{tabular}{|l|} 
AA item \\
$\begin{array}{l}\text { 1. Perform equipment } \\
\text { maintenance }\end{array}$ \\
\end{tabular}} & \multicolumn{3}{|c|}{$\begin{array}{c}\text { PTA pre-test } \\
\% \text { correct, } \% \text { uncertain }\end{array}$} & \multicolumn{3}{|c|}{$\begin{array}{c}\text { PTA post-test } \\
\% \text { correct, } \% \text { uncertain }\end{array}$} & \multicolumn{3}{|c|}{$\begin{array}{c}\text { DPT pre-test } \\
\% \text { correct, } \% \text { uncertain }\end{array}$} & \multicolumn{3}{|c|}{$\begin{array}{c}\text { DPT post-test } \\
\% \text { correct, \% uncertain }\end{array}$} \\
\hline & 73.7 & \multicolumn{2}{|c|}{10.5} & 61.1 & \multicolumn{2}{|c|}{16.7} & 81.1 & \multicolumn{2}{|c|}{18.9} & 75.0 & \multicolumn{2}{|c|}{19.4} \\
\hline $\begin{array}{l}\text { 2. Participate in quality assurance } \\
\text { program }\end{array}$ & \multicolumn{2}{|c|}{78.9} & 21.1 & \multicolumn{2}{|c|}{88.9} & 11.1 & \multicolumn{2}{|c|}{75.7} & 21.6 & \multicolumn{2}{|c|}{75.0} & 19.4 \\
\hline 3. Order supplies from vendors & \multicolumn{2}{|c|}{36.8} & 47.4 & \multicolumn{2}{|c|}{55.6} & 44.4 & \multicolumn{2}{|c|}{48.6} & 35.1 & \multicolumn{2}{|c|}{44.4} & 27.8 \\
\hline $\begin{array}{l}\text { 4. Plan PTA staff development } \\
\text { program }\end{array}$ & \multicolumn{2}{|c|}{52.6} & 26.3 & \multicolumn{2}{|c|}{61.1} & 27.8 & \multicolumn{2}{|c|}{70.3} & 18.9 & \multicolumn{2}{|c|}{66.7} & 19.4 \\
\hline $\begin{array}{l}\text { 16. Delegate treatment tasks to a } \\
\text { physical therapy aide }\end{array}$ & \multicolumn{2}{|c|}{15.8} & 26.3 & \multicolumn{2}{|c|}{5.6} & 22.2 & \multicolumn{2}{|c|}{13.5} & 21.6 & \multicolumn{2}{|c|}{22.2} & 16.7 \\
\hline Item & & A pre-t & & & A post & -test & & T pre- & & & P post-t & \\
\hline & Yes & No & DNK & Yes & No & DNK & Yes & No & DNK & Yes & No & DNK \\
\hline $\begin{array}{l}\text { 5. Manage physical therapist } \\
\text { recruitment, employment, } \\
\text { dismissal }\end{array}$ & 0 & 78.9 & 21.1 & $11.1^{*}$ & 77.8 & 11.1 & 5.4 & 67.6 & 27.0 & 5.6 & 75.0 & 19.4 \\
\hline $\begin{array}{l}\text { 6. Select capital equipment to be } \\
\text { purchased }\end{array}$ & 5.3 & 57.9 & 36.8 & $16.7^{*}$ & 27.8 & 55.6 & 16.2 & 43.2 & 40.5 & 33.3 & 36.1 & 30.6 \\
\hline $\begin{array}{l}\text { 7. Design fiscal management } \\
\text { system }\end{array}$ & 5.3 & 68.4 & 26.3 & $11.1^{*}$ & 44.4 & 44.4 & 21.6 & 43.2 & 35.1 & 25.0 & 41.7 & 33.3 \\
\hline $\begin{array}{l}\text { 8. Manage PTA recruitment, } \\
\text { employment, dismissal }\end{array}$ & 21.1 & 52.9 & 26.3 & $16.7^{*}$ & 50.0 & 33.3 & $38.9^{*}$ & 30.6 & 30.6 & 34.3 & 34.3 & 31.4 \\
\hline $\begin{array}{l}\text { 9. Plan physical therapist staff } \\
\text { development program }\end{array}$ & 0 & 78.9 & 21.1 & $5.6^{*}$ & 72.2 & 22.2 & 2.7 & 75.7 & 21.6 & 2.8 & 69.4 & 27.8 \\
\hline $\begin{array}{l}\text { 10. Develop physical therapy } \\
\text { policies/procedures }\end{array}$ & 10.5 & 73.7 & 15.8 & $5.9^{* *}$ & 76.5 & 17.6 & 0 & 81.1 & 18.9 & 5.6 & 69.4 & 25.0 \\
\hline $\begin{array}{l}\text { 11. Manage physical therapy aide } \\
\text { recruitment, employment, } \\
\text { dismissal }\end{array}$ & 26.3 & 36.8 & 36.8 & $22.2^{*}$ & 44.4 & 33.3 & 35.1 & 35.1 & 29.7 & 36.1 & 27.8 & 36.1 \\
\hline 12. Develop quality assurance plan & 26.3 & 36.8 & 36.8 & $38.9^{*}$ & 38.9 & 22.2 & $27.0^{*}$ & 21.6 & 51.4 & 40.0 & 20.0 & 40.0 \\
\hline $\begin{array}{l}\text { 13. Develop space management } \\
\text { program }\end{array}$ & 26.3 & 26.3 & 47.4 & $55.6^{*}$ & 22.2 & 22.2 & $43.2^{*}$ & 18.9 & 37.8 & 48.6 & 14.3 & 37.1 \\
\hline 14. Develop clinical research project & 63.2 & 5.3 & 31.6 & $77.8^{*}$ & 5.6 & 16.7 & 37.8 & 27.0 & 35.1 & 50.0 & 16.7 & 33.3 \\
\hline 15. Conduct clinical research project & 57.9 & 0 & 42.1 & $83.3^{*}$ & 0 & 16.7 & 37.8 & 29.7 & 32.4 & 55.6 & 16.7 & 27.8 \\
\hline
\end{tabular}

Journal of Research in Interprofessional

Practice and

Education

Vol. 5.1

March 2015 


\section{JRIPE}

Student Perceptions of the PTA's Role

Colgrove, Walton, \& VanHoose

\section{Figure legends}

Figure 1: Percentage of responses to patient evaluation (PE) items. Dashed lines represent $75 \%$ to determine level of accurate responses.

A. Percentage of survey items that improved more than $3 \%$ in the PTA cohort.

B. Percentage of survey items that declined more than 3\% in the PTA cohort.

C. Percentage of uncertainty in survey items that changed more than $3 \%$ in the PTA cohort.

D. Percentage of survey items that improved more than $3 \%$ in the DPT cohort with significant improvement in three items: PE 3 ( $p=$ $.017), \operatorname{PE} 22(p=.034)$ and PE $23(p=.026)$. Significant differences between cohort pre- and post-test scores indicated with *.

E. Percentage of survey items that declined more than 3\% in the DPT cohort.

F. Percentage of uncertainty in survey items that changed more than $3 \%$ in the DPT cohort.

Figure 2: Percentage of responses to treatment planning (TP) items

A. Percentage of survey items that improved more than $3 \%$ in the PTA cohort with significant improvement in one item, TP 12 ( $p=$ .048). Significant differences between cohort pre- and post-test scores indicated with *.

B. Percentage of survey items that declined more than 3\% in the PTA cohort with significant decline in item TP $3(p=.009)$. Significant differences between cohort pre- and post-test scores indicated with ${ }^{*}$.

C. Percentage of uncertainty in survey items that changed more than $3 \%$ in the PTA cohort.

D. Percentage of survey items that improved more than $3 \%$ in the DPT cohort with significant improvement in two items, TP 2 ( $p=$ $.032)$ and TP $5(p=.000)$. Significant differences between cohort pre- and post-test scores indicated with ${ }^{*}$.

E. Percentage of survey items that declined more than $3 \%$ in the DPT cohort.

F. Percentage of uncertainty in survey items that changed more than $3 \%$ in the DPT cohort. 


\section{JRIPE}

Student Perceptions of the PTA's Role

Colgrove, Walton, \& VanHoose
Journal of Research in Interprofessional Practice and Education

Figure 3: Percentage of responses to treatment implementation (TI) items

A. Percentage of survey items that improved more than $3 \%$ in the PTA cohort with significant improvement in item $23(p=.007)$. Significant differences between cohort pre- and post-test scores indicated with *.

B. Percentage of survey items that declined more than $3 \%$ in the PTA cohort.

C. Percentage of uncertainty in survey items that changed more than $3 \%$ in the PTA cohort.

D. Percentage of survey items that improved more than $3 \%$ in the DPT cohort with significant improvement in 8 items: TI 7 ( $p=$ $.047)$, TI 8 ( $p=.046)$, TI 13 ( $p=.003)$, TI $14(p=.007)$, TI $17(p=$ $.000)$, TI $19(p=.009)$, TI $23(p=.049)$, and TI $24(p=.002)$. Significant differences between cohort pre- and post-test scores indicated with *.

E. Percentage of survey items that declined more than $3 \%$ in the DPT cohort.

F. Percentage of uncertainty in survey items that changed more than $3 \%$ in the DPT cohort.

Figure 4: Percentage of responses to administrative activity (AA) items

Percentages of changes between pre and post surveys of each group are noted in the grouped bars with green indicating levels of uncertainty, red indicating it is not within the PTA role, and blue indicating it is within the PTA role.

A. The majority of all students indicated that items 5, 9, and 10 are outside the scope of PTA practice.

B. The majority of both cohorts of students became more accepting of the PTA role in items 13-15 and less uncertain following intervention.

C. The PTA cohort became more accepting or more uncertain of fiscal management items than the DPT students.

D. Both groups of students appear to be relatively split in approval, disapproval, and uncertainty in the PT aide management and the quality improvement functions of the PTA. 
20

Student Perceptions

of the PTA's Role

Colgrove, Walton,

\& VanHoose

Figure 1

Figure 1
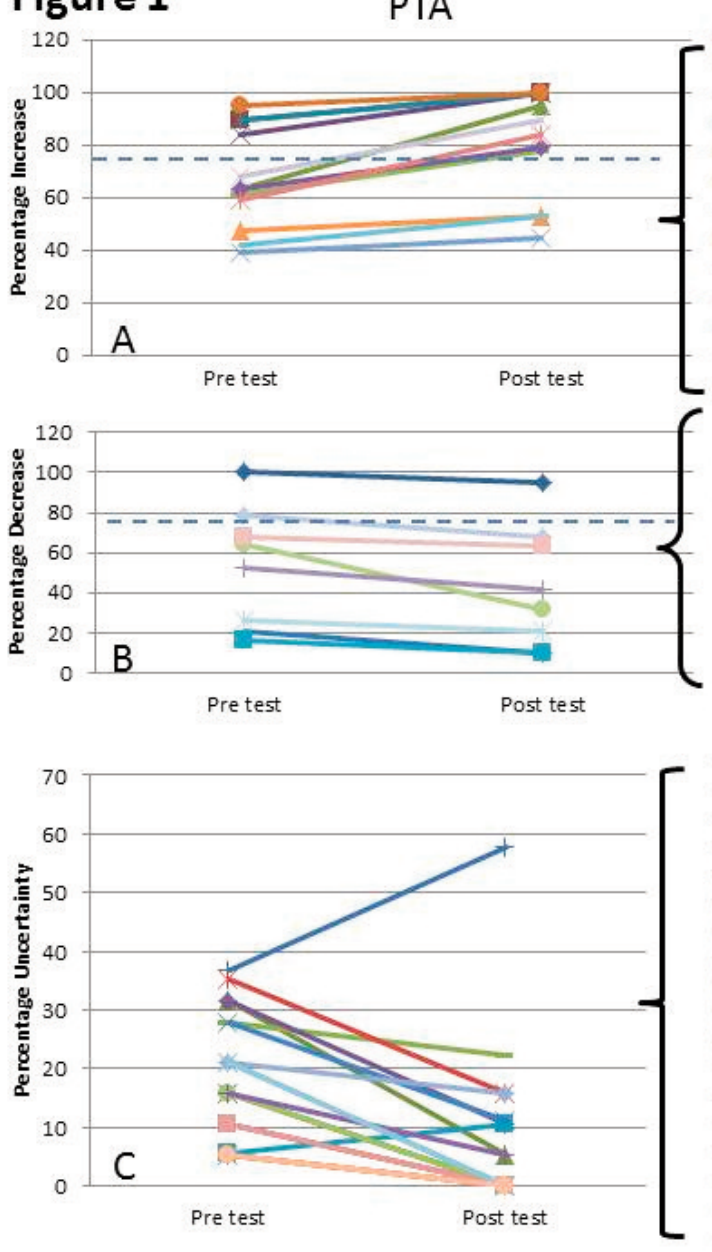
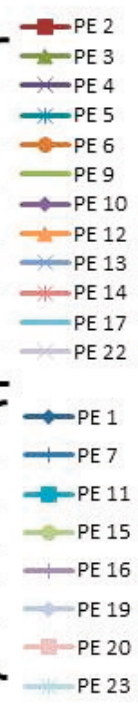

-PE 2 $-P E 3$
$\sim P E$ -PE 5 $\rightarrow$ PE 6 -PE 7 -PE 9 $\rightarrow$ PE 10 - - PE 11 $\simeq$ PE 13

\#-PE 14 $\leadsto$ PE 15 -PE 16

$\longrightarrow$ PE 19

-P PE 20

$\longrightarrow$ PE 22

-PE 23

-PE 24
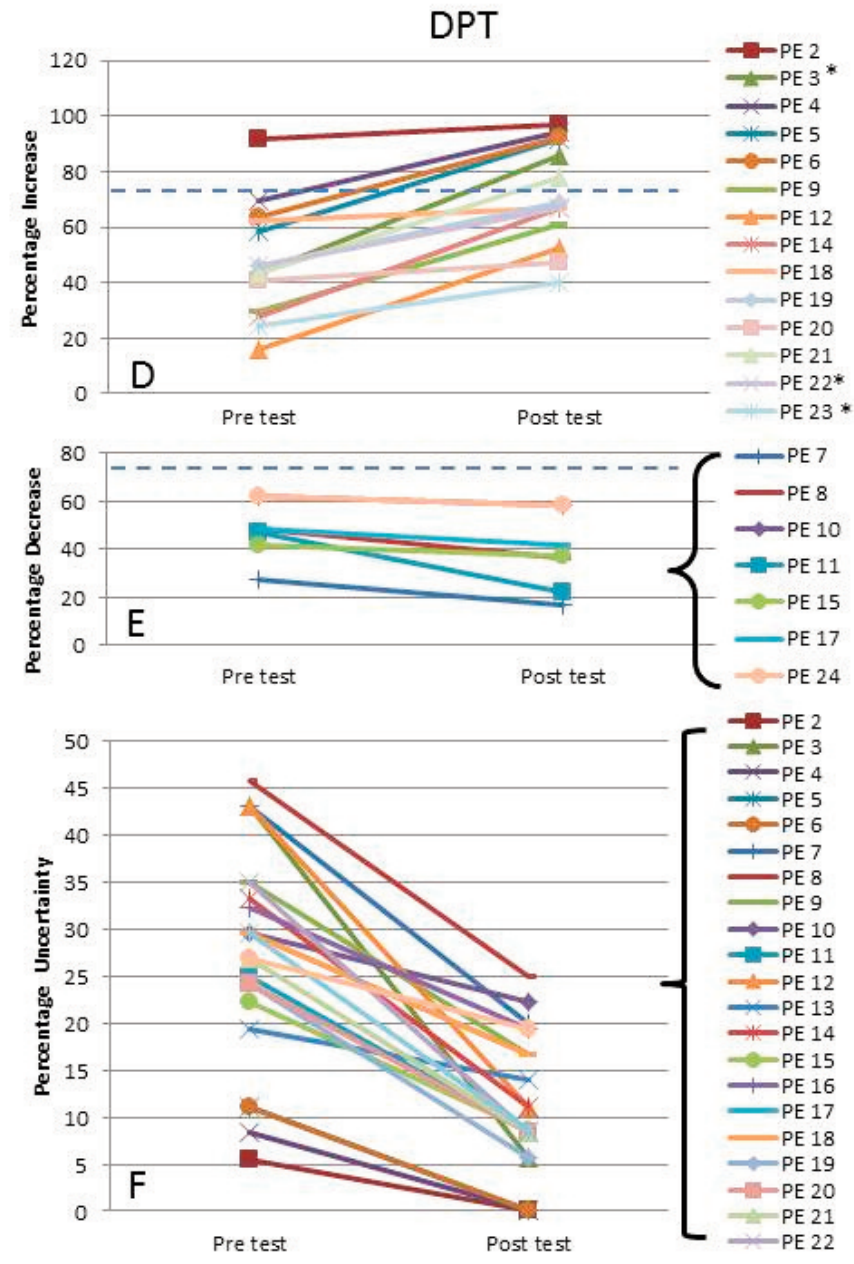

Journal of Research in Interprofessional

Practice and

Education

Vol. 5.1

March 2015 
21

Student Perceptions

of the PTA's Role

Colgrove, Walton,

\& VanHoose

Figure 2

\section{Figure 2}
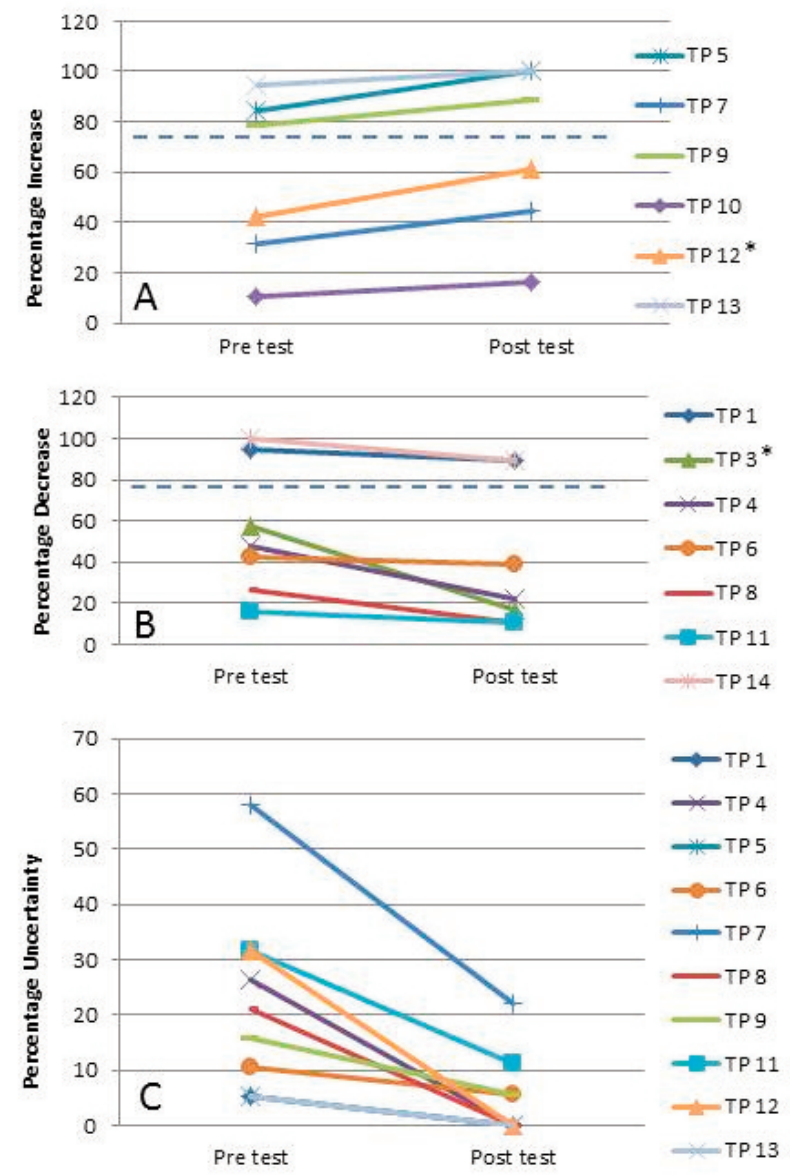
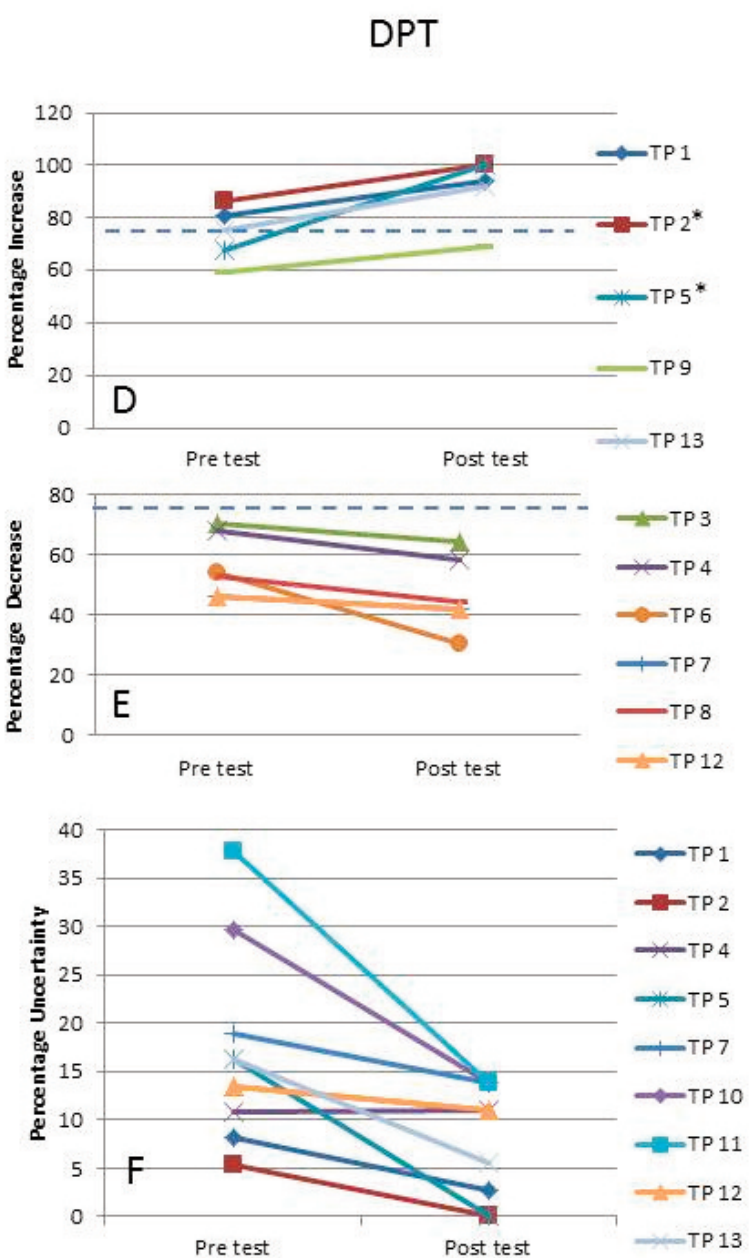

Journal of Research in Interprofessional

Practice and

Education

Vol. 5.1

March 2015 
Student Perceptions

of the PTA's Role

Colgrove, Walton,

\& VanHoose

Figure 3

Figure 3
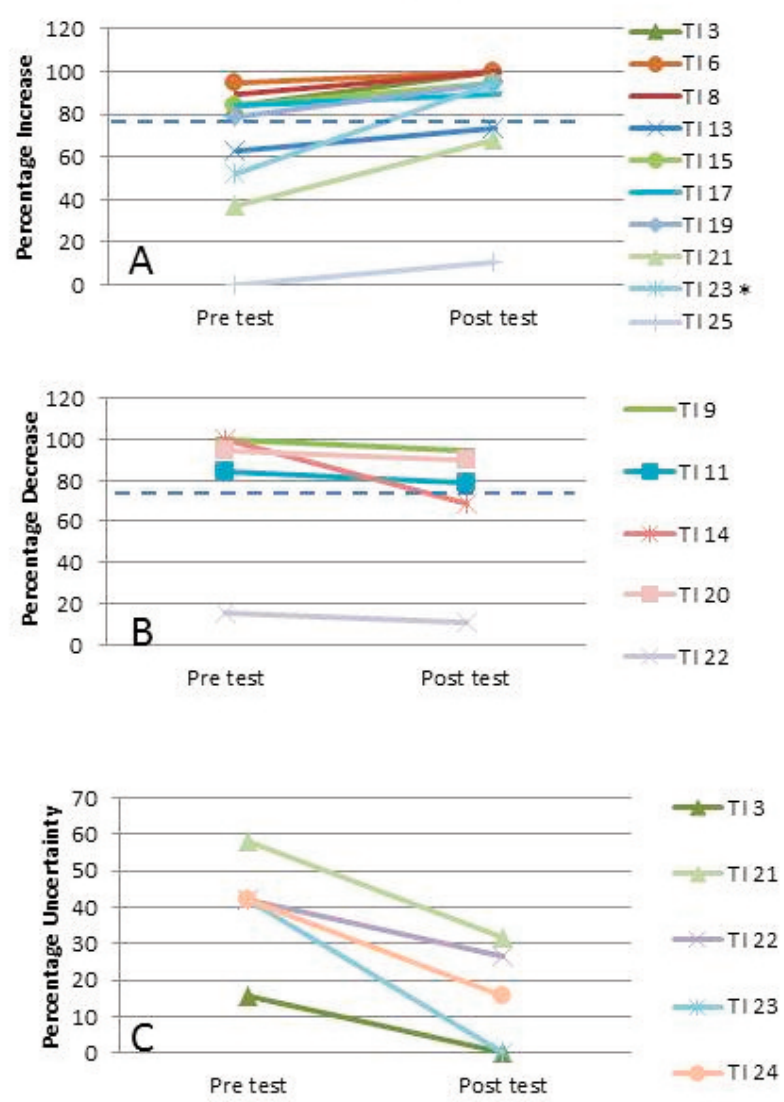
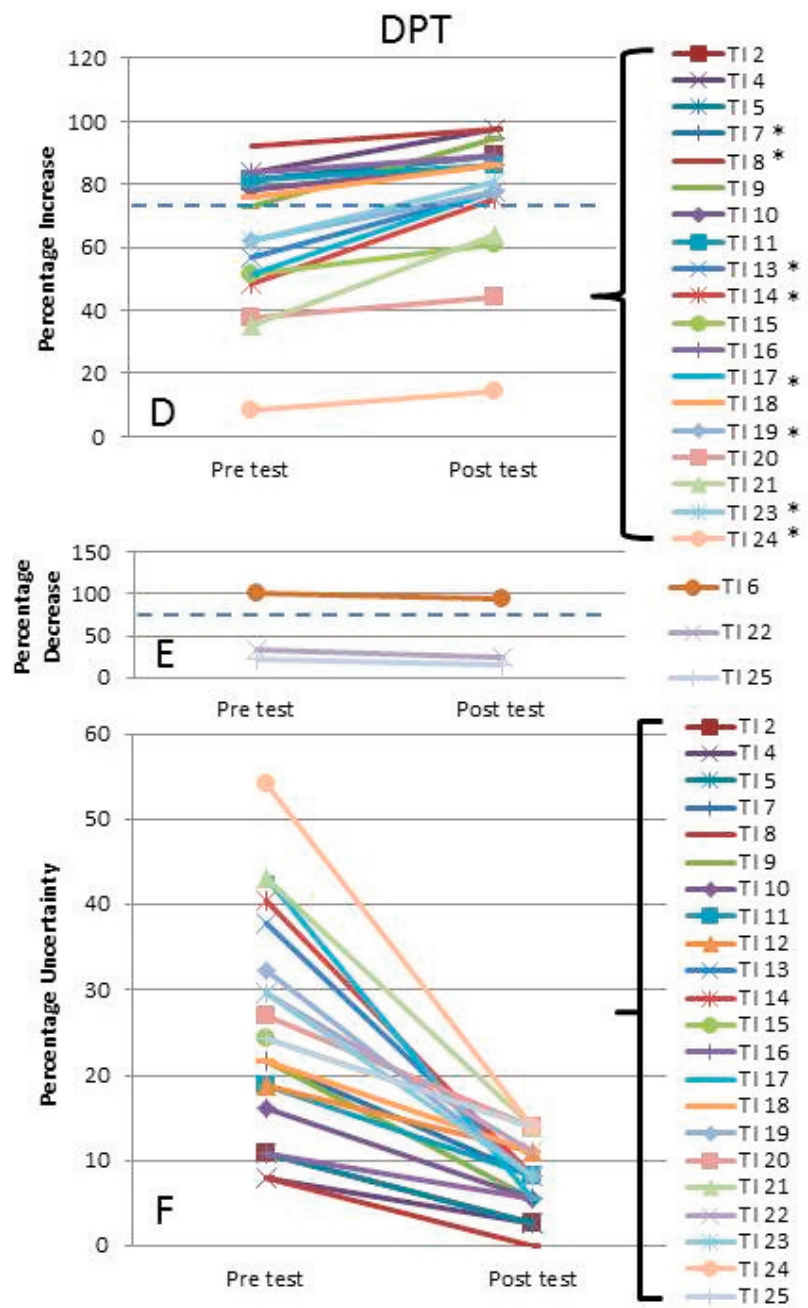

Journal of Research in Interprofessional

Practice and

Education

Vol. 5.1

March 2015 
23

Student Perceptions of the PTA's Role

Colgrove, Walton, \& VanHoose
Figure 4

AA 5 AA 9

AA 10

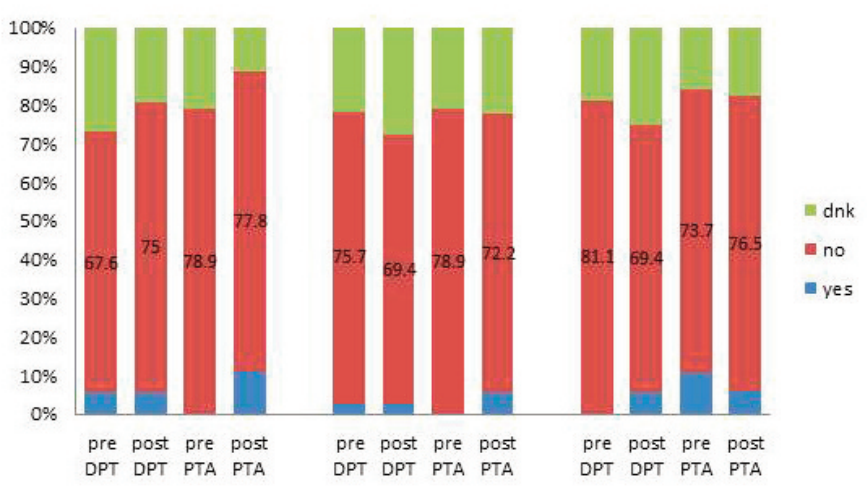

AA 13

AA 14

AA 15

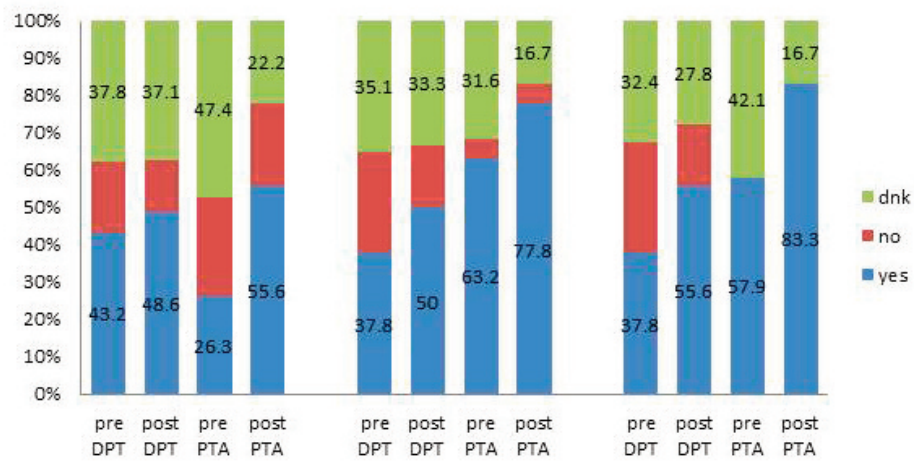

AA 6

AA 7

AA 8

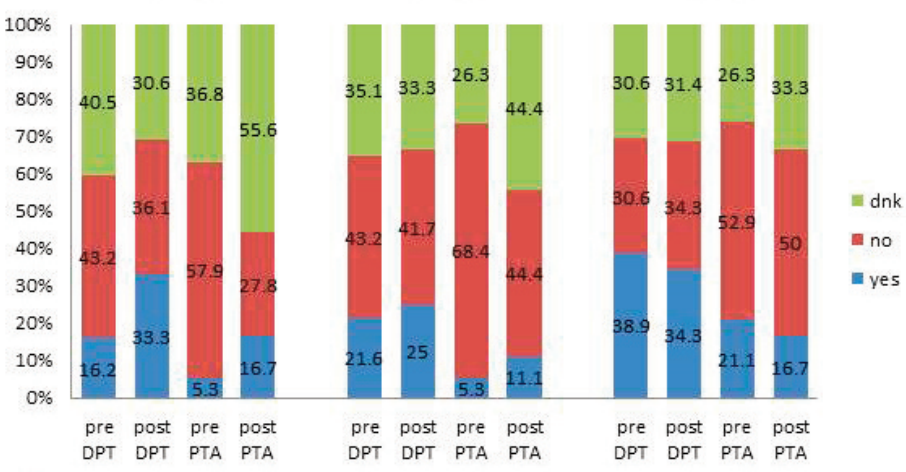

AA 11

AA12

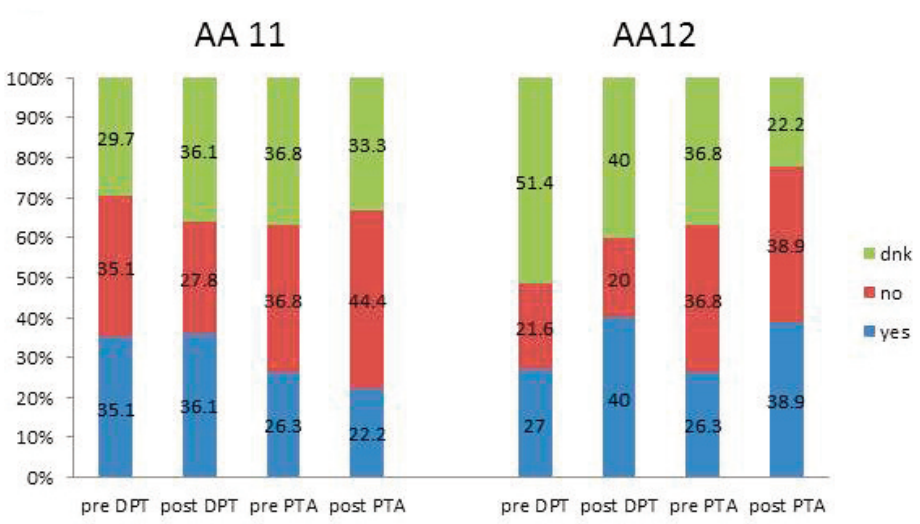

Journal of Research in Interprofessional

Practice and

Education

Vol. 5.1

March 2015
D Response rates 


\section{JRIPE}

24

Student Perceptions of the PTA's Role

Colgrove, Walton,

\& VanHoose
Journal of Research in Interprofessional Practice and Education

Vol. 5.1

March 2015

\section{Answer revision sources}

\begin{tabular}{|c|c|}
\hline Perform perceptual tests & $\begin{array}{l}\text { Check level of dexterity, co-ordination, and agility (BP) } \\
\text { Check ability to initiate, modify, and control movement patterns and postures (BP) } \\
\text { Observation of co-ordination, movement patterns, and motor skill and sensorimotor } \\
\text { function (NM) } \\
\text { Perform perceptual training (NM - Procedural Intervention) }\end{array}$ \\
\hline $\begin{array}{l}\text { Perform developmental } \\
\text { level tests }\end{array}$ & $\begin{array}{l}\text { Perform tests of developmental reflexes and reactions (BP) } \\
\text { Assess acquisition and evolution of motor skills (BP) } \\
\text { Sensorimotor function including postural reflexes and reactions, primitive reflexes and } \\
\text { reactions (NM) } \\
\text { Identify the presence or absence of developmental reflexes, associated reactions, or } \\
\text { abnormal tone (MS) }\end{array}$ \\
\hline $\begin{array}{l}\text { Test sensorimotor } \\
\text { function }\end{array}$ & $\begin{array}{l}\text { Perform tests of sensorimotor integration (BP) } \\
\text { Check peripheral nerve integrity (BP) } \\
\text { Check spinal nerve integrity (BP) } \\
\text { Sensorimotor function including postural reflexes and reactions, primitive reflexes and } \\
\text { reactions (NM) } \\
\text { Sensations (NM) } \\
\text { Identify the presence or absence of developmental reflexes, associated reactions, or } \\
\text { abnormal tone (MS) }\end{array}$ \\
\hline $\begin{array}{l}\text { Test accessory joint } \\
\text { motions }\end{array}$ & $\begin{array}{l}\text { Perform tests of peripheral joint mobility (e.g., glide) (BP) } \\
\text { Joint active and passive movement (e.g., palpation) (NM) }\end{array}$ \\
\hline $\begin{array}{l}\text { Perform specific manual } \\
\text { muscle testing }\end{array}$ & $\begin{array}{l}\text { Perform tests of muscle strength, power, and endurance (BP) } \\
\text { Muscle strength, power, and endurance (e.g., selected manual muscle tests) (NM) } \\
\text { Perform manual muscle testing (MS) }\end{array}$ \\
\hline Assess muscle tone & $\begin{array}{l}\text { Check muscle tone (BP) } \\
\text { Muscle length, soft tissue extensibility, tone, and flexibility (NM) } \\
\text { Describe changes in muscle tone (MS) } \\
\text { Identify the presence or absence of developmental reflexes, associated reactions, or } \\
\text { abnormal tone (MS). }\end{array}$ \\
\hline
\end{tabular}

Minimum skill (MS) [7] and normative model (NM) [6] listed examples of data collection techniques; Federation of State Boards of Physical Therapy Practice Analysis (BP) [8] is under Patient Assessment: Data Collection Techniques unless otherwise indicated. 